\title{
Performance Improvement of a Boil-off Gas Re-condensation Process with Pre- cooling at LNG Terminals
}

\author{
Yuan Zongming ${ }^{1}$, Cui Mengmeng ${ }^{1} *$, Song Rui ${ }^{2}$, Xie Ying ${ }^{1}$ and Han Lili ${ }^{3}$ \\ ${ }^{1}$ School of Petroleum and Natural Gas Engineering, Southwest Petroleum University, Chengdu, 610500, China \\ ${ }^{2}$ School of Geoscience and Technology, Southwest Petroleum University, Chengdu, 610500, China \\ ${ }^{3}$ China Petroleum Engineering CO., LTD. Southwest Company, Chengdu, 610017, China \\ E-mail: *cuimm619@163.com
}

Received 26 May 2014, Revised 22 July 2014, Revised 24 August 2014, Revised 13 October 2014, Revised 25 December 2014, Accepted 09 March 2015

\begin{abstract}
Since liquefied natural gas (LNG) is stored at a temperature of about $-160^{\circ} \mathrm{C}$ under ambient pressure, it is unable to avoid unexpected generation of boil-off gas (BOG) from LNG storage tanks due to heat transfer from the surroundings to the cryogenic system. Reasonable and effective treatment of BOG, can not only reduce the waste of energy at LNG terminals, but also guarantee the safety and stability of the system. This paper puts up with a novel process to condense the double-stage pre-cooled and compressed BOG by means of heat transfer with LNG. With the aim of minimizing the total power consumption, Aspen HYSYS is employed to simulate and optimize the process. It is indicated that system performance has been improved in comparison with the direct compression process and the re-condensation process with single-stage pre-cooling. Engineering issues about this process are discussed, simultaneously.
\end{abstract}

Keywords: Boil-off gas; re-condensation; pre-cooling; optimization.

\section{Introduction}

Benefit from the technical and economic advantages of natural gas, an unceasing growth of power consumption in households, industry, and power plants has gradually turned it into a major source of energy. According to the U.S. Energy Information Administration [1], the global total natural gas consumption increases by 1.7 percent per year on average, from 113 trillion cubic feet in 2010 to 132 trillion cubic feet in 2020 and 185 trillion cubic feet in 2040. To satisfy such a demand, liquefied natural gas (LNG) is expected to play an increasingly important role in the natural gas industry and energy markets with the growth of about 10 percent a year in the next 10 years [2] on account of the ease of transport [3].

Many researchers have focused on the efficiency analysis of different liquefaction processes. To improve the energy efficiency of the natural gas liquefaction process, Lim et al. [4] have investigated the energy recovery savings potentials of different configurations. He et al. [5] have put up with a novel process to liquefy the pipeline natural gas by utilizing its available exergy. An experimental investigation of the cold storage with liquid/solid phase change of water has been conducted based on the cold energy recovery of LNG refrigerated vehicles [6]. Wang $e t$ al. [7] have performed a thermodynamic-analysis-based study of the minimization of the power consumption of a typical natural gas liquefaction process. Although a lot of researches have been conducted in natural gas liquefaction plants, peak shaving processes in skid-mounted packages and the recovery of associated gas and stranded gas, process performance improvement at LNG receiving terminals is worthy of further study.
LNG receiving terminals have been worldwide built, with a total number of about 100 on-stream until April 2014 [8]. Since LNG is stored at the temperature as low as about $-160^{\circ} \mathrm{C}$, it is unable to avoid unexpected generation of boiloff gas (BOG) from LNG storage tanks due to heat transfer from the surroundings to the cryogenic system. Evaporation losses are estimated to be $0.05 \%-0.1 \%$ per day of the tank contents [9] and would be more serious during cargos unloading. Thus, how to handle BOG becomes relevant.

Based on environmental and economic considerations, BOG is rarely disposed for direct combustion nowadays. The current treatment processes for BOG can be broadly divided into two kinds: the direct compression process (Figure 1) and the re-condensation process. Although the direct compression process is simple in device, it has been proven that the energy-utilization efficiency of BOG recondensation system is $30 \%-60 \%$ higher than that of compressing BOG directly to a distribution pipeline [10]. Meanwhile, the re-condensation process is proven to require $50 \%$ lower power consumption and less maintenance [11].

In view of this, the improvement and optimization of the process and facilities for BOG re-condensation have been emphasized by many scholars recently. Jung et al. [12] have come up with recommendations for the design and operation of the re-condensation process. Shin et al. [13] have proposed a method for optimization of BOG compressor operation to minimize power consumption based on a mixed integer linear problem formulation, and refine the operation policies based on a safety analysis on the dynamics of the tank pressure. Another dynamic simulation has been conducted for an optimal BOG 
condensation operation strategy [14]. Based on the practical data of Da-Peng LNG terminal in China, Li et al. $[15,16]$ have improved the traditional re-condensation process by pre-cooling BOG (Figure 2), which saves $32.5 \%$ of the total compressor power consumption. Simultaneously, Park et al. [17] have also conducted a research of the re-condensation process to pre-cool BOG by the cryogenic LNG stream, providing a $22.7 \%$ energy saving ratio. To reduce power consumption, Chen [18] has proposed a BOG multi-stage compression and condensation process (Figure 3 ) based on Pro-II software simulation, which saves energy by more than $30 \%$ and improves BOG load capacity by $11.9 \%$.

The current BOG treatment processes have reduced energy waste to a certain degree, but there are still some shortcomings. Although the direct compression process is simple in device and low in investment, power consumption increases significantly with the growth of user pressure requirements. Power consumption has been reduced by the BOG re-condensation process with single-stage pre-cooling
[16], but the pressure ratio of BOG compressor is too high, which restricts the efficiency of compressor. Through an analysis of multi-stage compression and condensation process [18], a two-stage process proves to be more suitable for BOG management in LNG terminals.

By a combination of the BOG re-condensation process with single-stage pre-cooling with the BOG multi-stage compression and condensation process, a novel BOG recondensation process with double-stage pre-cooling is obtained in this paper (Figure 4). Energy balance and thermodynamic analysis are applied to the process. With the aim of minimizing the total power consumption, key parameters influencing the process performance are optimized. Detailed comparison and analysis are presented between the former BOG treatment processes and the proposed process. The sensitivity analysis of the process towards BOG flow rate is conducted. Several issues have been explained for engineering application of this process.

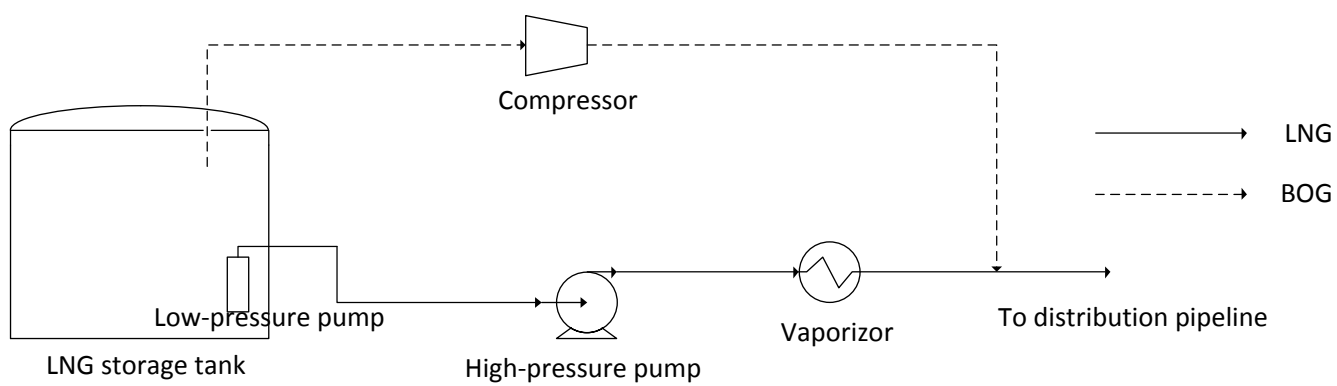

Figure 1. BOG direct compression process.

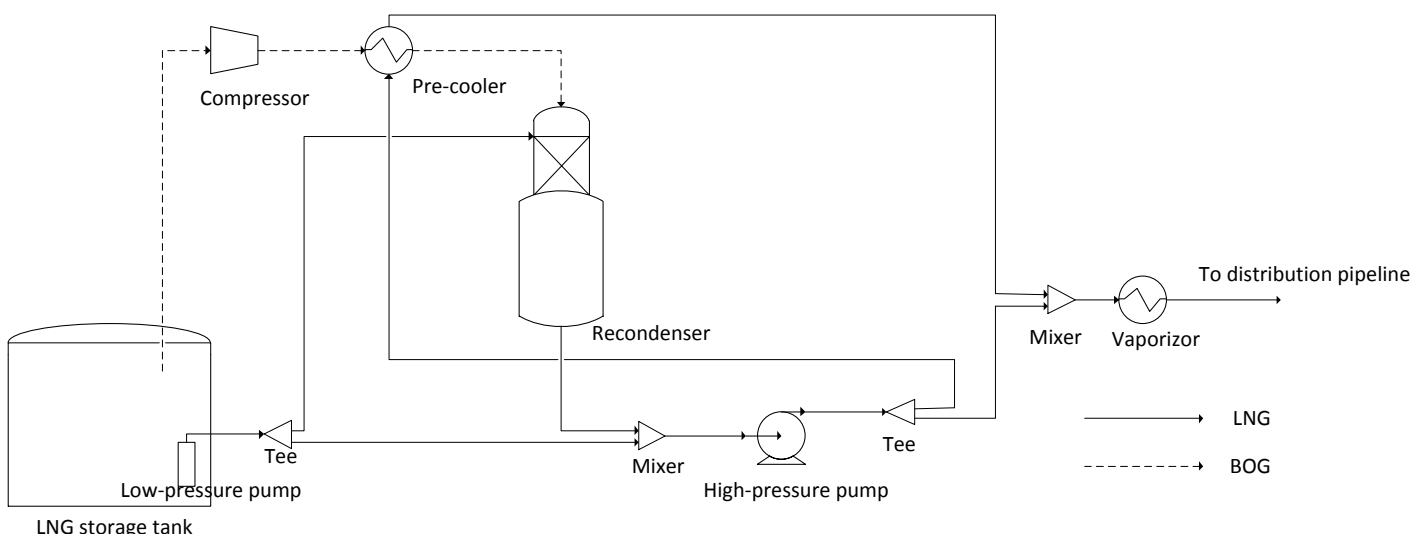

Figure 2. BOG re-condensation process with single-stage pre-cooling.

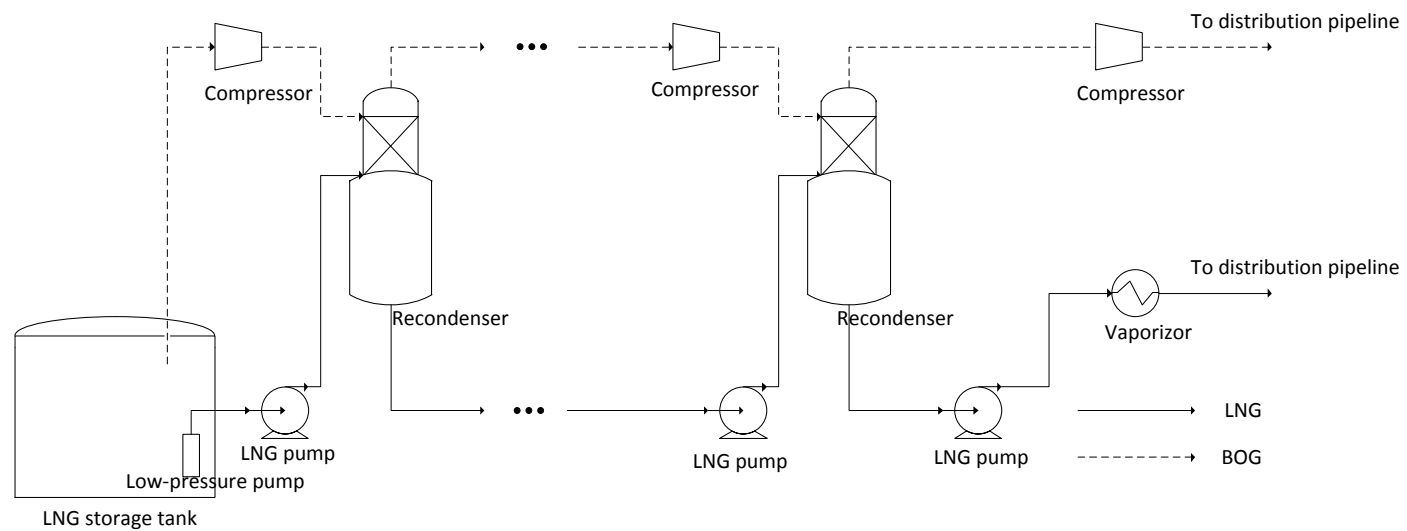

Figure 3. BOG multi-stage compression and condensation process. 


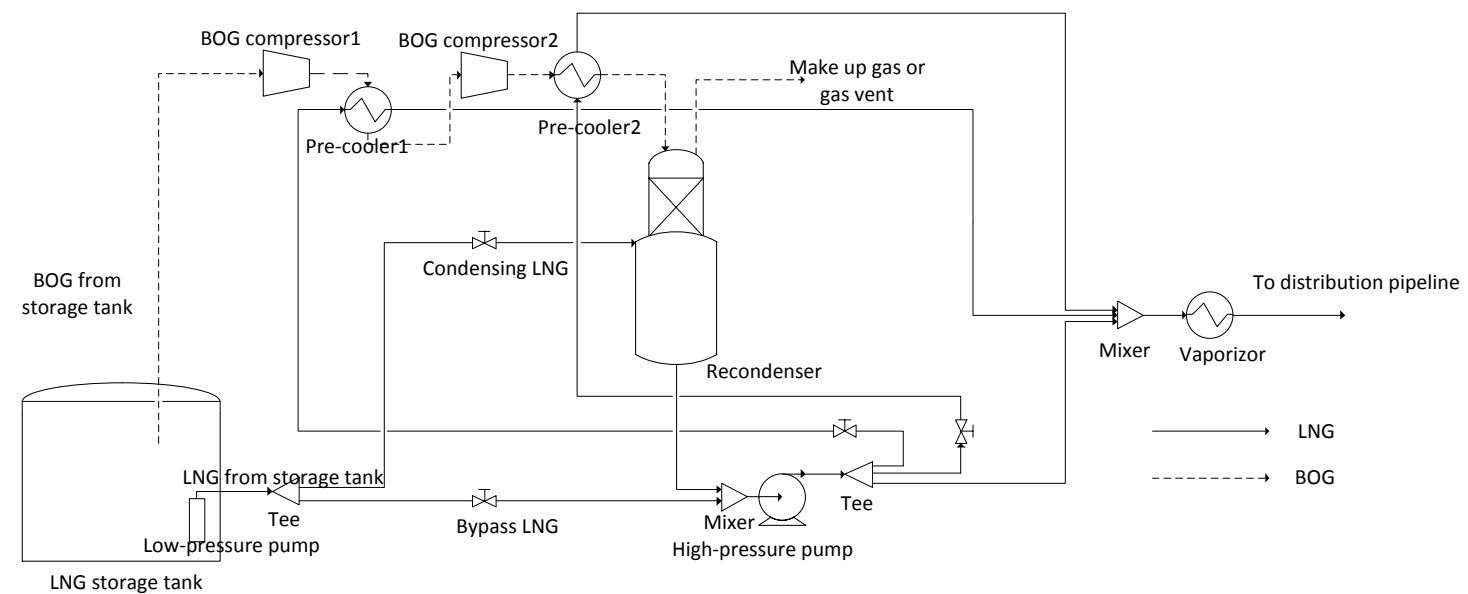

Figure 4. BOG re-condensation process with double-stage pre-cooling.

\section{Process Description and Constraint Conditions}

As Figure 4 depicts, in the BOG re-condensation process with double-stage pre-cooling, LNG from the lowpressure pump (LP) is split into two streams. One stream (hereinafter, referred to as condensing LNG stream) flows directly into the top of the BOG re-condenser (BR) to condense BOG, which has been cooled in the pre-coolers after compressed by the BOG compressors (BC). The other stream (hereinafter, referred to as bypass LNG stream) converges with the condensate flowing from the bottom of the BR. High-pressure pump (HP) is employed to improve the pressure of LNG. Two branch of high pressure LNG are routed to the pre-coolers for reducing the BOG temperature. Finally the total LNG flows into the open rack vaporizer (ORV), where LNG performs indirect heat exchange with seawater for vapor phase to the distribution pipeline. The mole fraction of each component for LNG and the known parameters in the process are given in Table 1.

\section{Thermodynamic Analysis}

Simulation and optimization of the process is conducted using Aspen HYSYS [19] software, and the simulation model is shown in Figure 5.

Table 1. The Mole Fraction of Components for $L N G$ and the Known Parameters.

\begin{tabular}{|c|c|c|}
\hline Parameters & Value & Refs./Notes \\
\hline LNG storage pressure & $116.6 \mathrm{kPa}$ & {$[16,18]$} \\
\hline LNG storage temperature & $-160^{\circ} \mathrm{C}$ & {$[16,18]$} \\
\hline LNG flow rate & $173.3 \mathrm{t} / \mathrm{h}$ & {$[16,18]$} \\
\hline Distribution pressure & $9000 \mathrm{kPa}$ & {$[16,18]$} \\
\hline Mole fraction of & $\mathrm{CH}_{4} \quad 88.774$ & {$[16,18]$} \\
\hline \multirow[t]{6}{*}{ LNG components } & $\mathrm{C}_{2} \mathrm{H}_{6} \quad 7.542$ & \\
\hline & $\mathrm{C}_{3} \mathrm{H}_{8} \quad 2.588$ & \\
\hline & $\mathrm{i}-\mathrm{C}_{4} \mathrm{H}_{10} \quad 0.454$ & \\
\hline & $\mathrm{n}-\mathrm{C}_{4} \mathrm{H}_{10} \quad 0.562$ & \\
\hline & $\mathrm{i}-\mathrm{C}_{5} \mathrm{H}_{12} \quad 0.004$ & \\
\hline & $\mathrm{N}_{2} \quad 0.074$ & \\
\hline BOG flow rate & $6.7 \mathrm{t} / \mathrm{h}$ & {$[16,18]$} \\
\hline $\begin{array}{l}\text { Pressure drop in heat } \\
\text { exchanger } \\
\text { and water-cooler }\end{array}$ & $0 \mathrm{kPa}$ & $\begin{array}{l}\text { To simplify the } \\
\text { process, } \\
\text { [5] }\end{array}$ \\
\hline Ambient temperature & $25^{\circ} \mathrm{C}$ & \\
\hline $\begin{array}{l}\text { The adiabatic efficiency } \\
\text { of compressor }\end{array}$ & $75 \%$ & {$[16,18]$} \\
\hline $\begin{array}{l}\text { The adiabatic efficiency } \\
\text { of pumps }\end{array}$ & $75 \%$ & {$[16,18]$} \\
\hline $\begin{array}{l}\text { Pressure ratio } \\
\text { of each compressor }\end{array}$ & $1.5-2.5$ & \\
\hline $\begin{array}{l}\text { The minimum approach } \\
\text { temperature of heat } \\
\text { exchanger }\end{array}$ & $>5^{\circ} \mathrm{C}$ & \\
\hline
\end{tabular}

In this study, every facility in the process is modeled with mass and energy balance. The energy balance of each component is defined based on input and output variables. Three assumptions are made for the process as the followings:

(1) The process is in steady state with negligible potential and kinetic energy effects.

(2) The adiabatic efficiency of two compressors and two pumps is $75 \%$.

(3) To simplify the simulation, pressure drop in heat exchanges is set to be zero [5].

\subsection{Compressors}

BOG firstly undergoes two stages of compression (C$101, \mathrm{C}-102)$ to a higher pressure. The required power is given by:

C-101:

$W_{101}=\dot{m}_{B O G}\left(h_{101}-h_{B O G}\right)=W_{\min 101} / \eta_{c 101}$

C-102:

$W_{102}=\dot{m}_{102}\left(h_{103}-h_{102}\right)=W_{\min 102} / \eta_{c 102}$

\subsection{Pre-coolers}

Pre-coolers are set after every stage of compression, in which heat transfer is performed between BOG and high pressure LNG. The heat transfer in Pre-cooler1 and Precooler2 can be calculated as follows:

Pre-cooler 1:

$Q_{p c 1}=\dot{m}_{101}\left(h_{102}-h_{101}\right)=\dot{m}_{208}\left(h_{211}-h_{208}\right)$

Pre-cooler 2:

$Q_{p c 2}=\dot{m}_{103}\left(h_{104}-h_{103}\right)=\dot{m}_{207}\left(h_{210}-h_{207}\right)$

\subsection{Pumps}

As the core equipment at LNG terminals, LP provides the pressure for LNG to flow out from the storage tank, while HP realizes the function of pressurizing LNG to the pressure for distribution. The required power is given by:

P-201:

$W_{201}=\dot{m}_{L N G}\left(h_{201}-h_{L N G}\right)=W_{\min 201} / \eta_{p 201}$

$$
\text { P-202: }
$$

$W_{202}=\dot{m}_{205}\left(h_{206}-h_{205}\right)=W_{\min 202} / \eta_{p 202}$ 


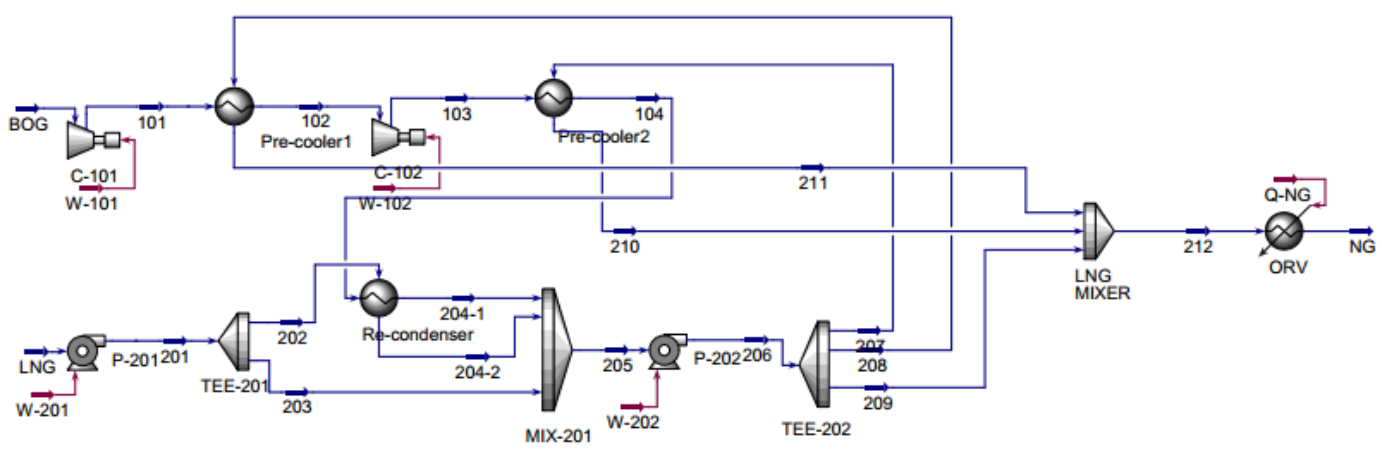

Figure 5. The simulation model of BOG re-condensation process with double-stage pre-cooling in Aspen HYSYS.

\subsection{Re-condenser}

Re-condenser is the main component for BOG condensation. Neglecting heat loss, the energy balance in the condenser is presented by:

Re-condenser:

$Q_{r c}=\dot{m}_{104}\left(h_{204-1}-h_{104}\right)=\dot{m}_{202}\left(h_{204-2}-h_{202}\right)$

\subsection{Mixers and Tees}

The energy balances in the mixer are given by:

Tee-201:

$$
\dot{m}_{201} h_{201}=\dot{m}_{202} h_{202}+\dot{m}_{203} h_{203}
$$

Tee-202:

$$
\dot{m}_{206} h_{206}=\dot{m}_{207} h_{207}+\dot{m}_{208} h_{208}+\dot{m}_{209} h_{209}
$$

Mix-201:

$$
\dot{m}_{204-1} h_{204-1}+\dot{m}_{204-2} h_{204-2}+\dot{m}_{203} h_{203}=\dot{m}_{205} h_{205}
$$

LNG Mixer:

$$
\dot{m}_{209} h_{209}+\dot{m}_{210} h_{210}+\dot{m}_{211} h_{211}=\dot{m}_{212} h_{212}
$$

\subsection{LNG Properties Calculation}

Soave-Redlich-Kwong (SRK) equation and Lee-KeslerPlocker (LKP) equation are selected for the fluid package in simulation, where SRK equation is used to calculate phase equilibrium and LKP equation is used to calculate enthalpy and entropy $[15,18,20]$. Since it is difficult to measure the BOG components by experimental methods [11], calculations for BOG properties have been done by Aspen HYSYS based on the LNG storage tank operation condition and LNG compositions [16,18]. The mole fraction of components for BOG is obtained by mass balance, heat balance and phase equilibrium (Table 2). All of the BOG is re-condensed. The thermodynamic cycle diagram with each point $(\mathrm{P}-\mathrm{T})$ is illustrated in Figure 6 , where the phase diagram of LNG is displayed as a state reference.

Table 2. The Mole Fraction of Components for BOG.

\begin{tabular}{ll}
\hline Parameters & Value \\
\hline BOG pressure & $116.6 \mathrm{kPa}$ \\
BOG temperature & $-160^{\circ} \mathrm{C}$ \\
Mole fraction of & $\mathrm{CH}_{4} \quad 97.90$ \\
BOG components & $\mathrm{C}_{2} \mathrm{H}_{6} \quad 0.02$ \\
& $\mathrm{~N}_{2} \quad 2.09$ \\
\hline
\end{tabular}

\section{Process Optimization}

\subsection{Objective Functions}

Total power consumption is selected as the major index for process optimization. The key parameters influencing the process performance are the outlet pressure of BOG compressors $\mathrm{p}_{101}, \mathrm{p}_{103}$, the outlet pressure after primary booster of LNG $\mathrm{p}_{201}$, the flow rate of LNG for lowering the temperature of $\mathrm{BOG} \mathrm{m}_{202}, \mathrm{~m}_{207}, \mathrm{~m}_{208}$, and the temperature of BOG after cooling $\mathrm{t}_{102}, \mathrm{t}_{104}, \mathrm{t}_{204-1}$. Here the pressure of BOG after the double-stage compressor $\left(\mathrm{p}_{103}\right)$ is set to be equal to the pressure of LNG after primary booster $\left(\mathrm{p}_{201}\right)$ to avoid additional pressure loss in mixers.

In this case, the optimization problem is finding out the optimum parameter values to make the total power consumption lowest, under the constraint conditions in the following:

(A) The minimum temperature difference between the hot and cold areas of fluid in heat exchangers cannot be less than $5^{\circ} \mathrm{C}$.

(B) The ratio of the outlet pressure and the inlet pressure of each compressor is between 1.5 and 2.5.

(C) Material streams entering the compressors must be vapor, while streams flowing out of the re-condenser must be liquid. This restriction can be adjusted by setting the upper and lower limits of the variables.

In brief, the objective function of process optimization can be expressed as

$f(X)=\min \left(W_{101}+W_{102}+W_{201}+W_{202}\right)$

With independent variables as follows:

$X=\left[\begin{array}{llllllll}p_{101} & p_{201} & m_{202} & m_{207} & m_{208} & t_{102} & t_{104} & t_{204-1}\end{array}\right]^{\mathrm{T}}$

Subjected to

$\min$ approach $(i) \geq 5$

( $i=$ pre-cooler 1, pre-cooler 2 ,re-condenser $)$

$\left\{\frac{p_{101}}{p_{B O G}}, \frac{p_{103}}{p_{102}}\right\} \in[1.5,2.5]$

\subsection{Optimization Results}

Aspen HYSYS contains a multi-variable steady-state Optimizer. Once the flowsheet has been built and a converged solution has been obtained, the Optimizer can be used to find the operating conditions which minimize (or maximize) the objective function $[19,21]$. There are four kinds of optimization modes: Original, Hyprotech SQP, MDC Optim, and Selection Optimization [19]. Any mode of Optimizer can be used in this case, but the Original mode is selected as default in Aspen HYSYS. The optimal results are shown in Table 3. The schematic of final optimized process with T, P for some streams is illustrated in Figure 7. 


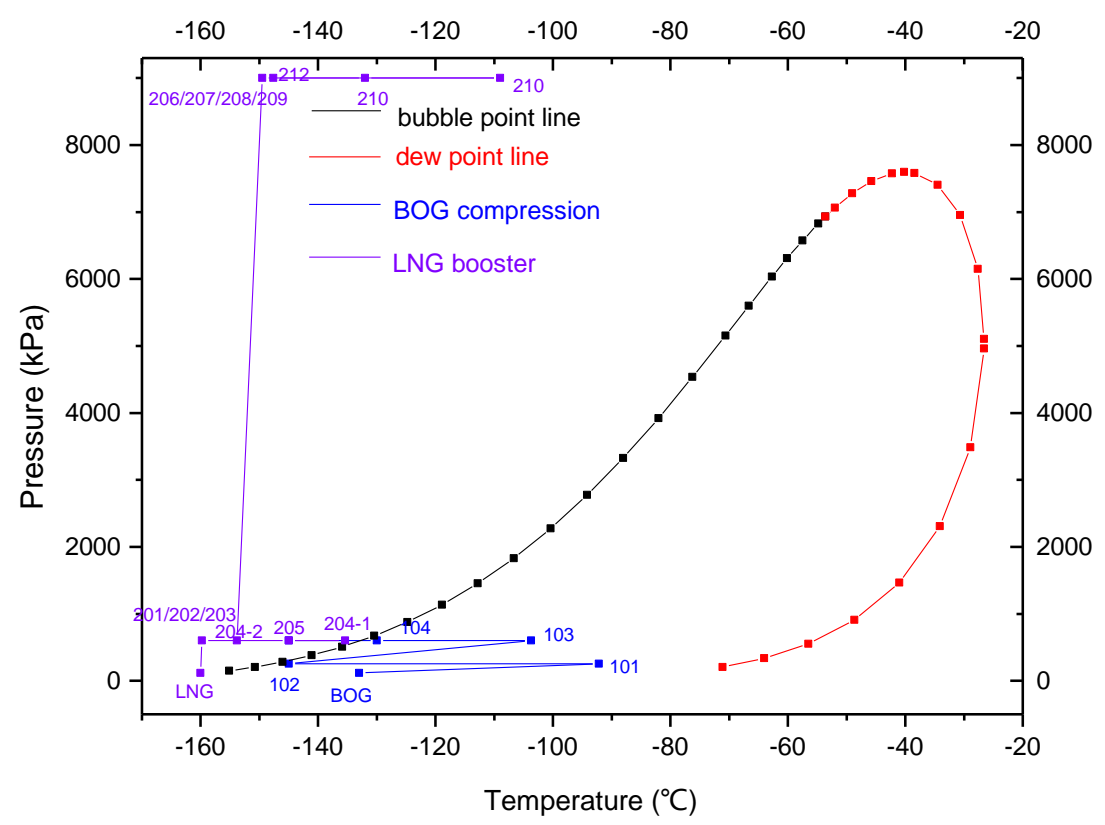

Figure 6. The thermodynamic cycle on temperature-pressure diagram.

Table 3. Optimization Results of the Process.

\begin{tabular}{|c|c|c|c|c|c|c|c|c|}
\hline Parameters & $p_{101}(\mathrm{kPa})$ & $p_{201}(\mathrm{kPa})$ & $m_{202}(\mathrm{t} / \mathrm{h})$ & $m_{207}(\mathrm{t} / \mathrm{h})$ & $m_{208}(\mathrm{t} / \mathrm{h})$ & $t_{102}\left({ }^{\circ} \mathrm{C}\right)$ & $t_{104}\left({ }^{\circ} \mathrm{C}\right)$ & $t_{204-I}\left({ }^{\circ} \mathrm{C}\right)$ \\
\hline Results & 250 & 600 & 40 & 3 & 13 & -145 & -130 & -145 \\
\hline
\end{tabular}

Through a double-stage pre-cooling of BOG, this process achieves the total power consumption of $1598 \mathrm{~kW}$, in which the total compressor power consumption is $297 \mathrm{~kW}$ and the total pump power consumption is $1301 \mathrm{~kW}$.

Taking the optimal results of the proposed process as a basis, simulations of the direct compression process with two-stage compression and the re-condensation process with single-stage pre-cooling are conducted. The direct compression process with two-stage compression occupies the total power consumption of $2691 \mathrm{~kW}$, in which the total compressor power consumption is $1462 \mathrm{~kW}$ and the total pump power consumption is $1229 \mathrm{~kW}$. The re-condensation process with single-stage pre-cooling [16] expends the total power consumption of $1656 \mathrm{~kW}$, in which the total compressor power consumption is $355 \mathrm{~kW}$ and the total pump power consumption is $1301 \mathrm{~kW}$. However, the singlestage compression ratio is higher than 5, beyond the common capacity of medium-sized compressors. Although the multi-stage compression and condensation process occupies almost the same total power consumption, total flow of LNG is conducted heat transfer with BOG, resulting in large LNG throughput in the re-condenser. Consequently, the process proposes higher requirements of re-condenser for larger size and more investment. With two streams of bypassing high pressure LNG, this process achieves the same purpose with lower investment by two small-scale pre-coolers.

In conclusion, this process is as effective as the twostage compression and condensation process, but able to save a re-condenser and connection pipelines. Compared with the direct compression process, this process reduces power consumption greatly more than $60 \%$. Although the total pump power consumption is the same as the recondensation process with single-stage pre-cooling, this process improves the process performance by increasing total compressor power consumption by almost $20 \%$. What's more, this process avoids high compression ratio by double-stage compression, which is more applicable to industry application.

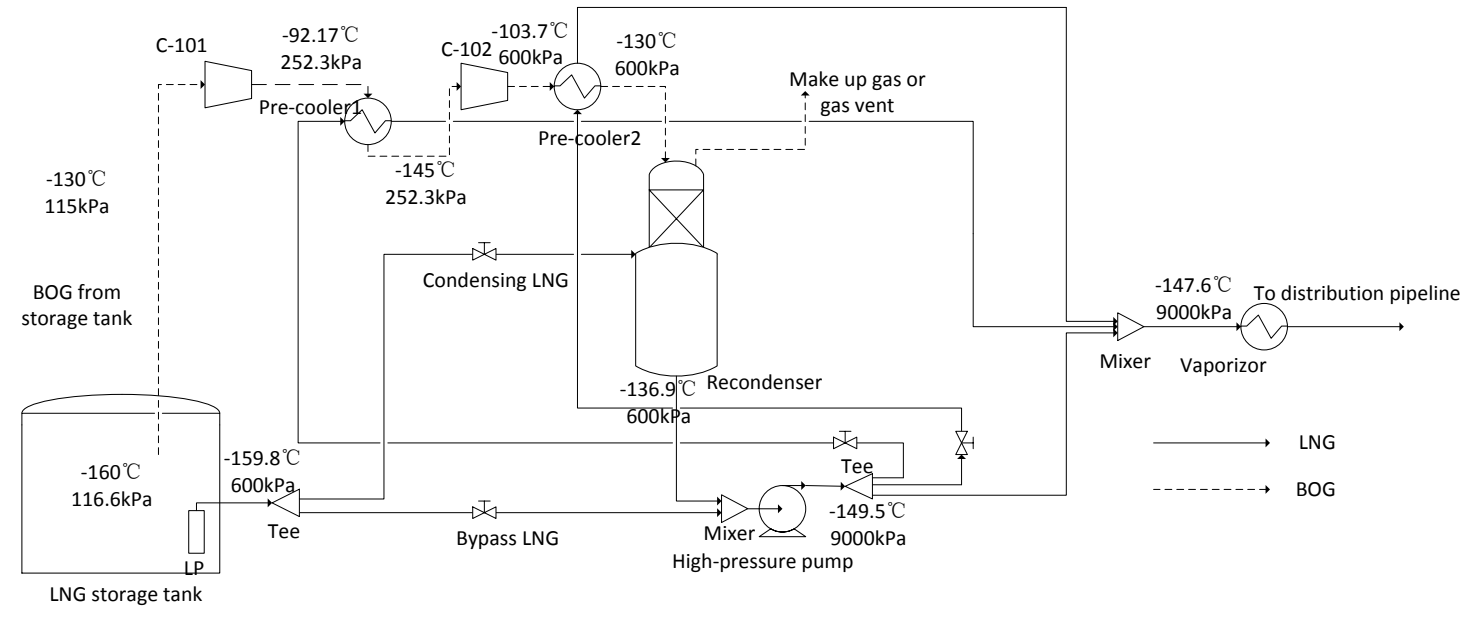

Figure 7. The schematic of final optimized process with T, P for some streams. 


\subsection{Sensitivity Analysis of BOG Flow Rate}

Flow rate of $\mathrm{BOG}$ varies at different operating conditions. During the sensitivity analysis of the total power consumption respect to BOG flow rate, the key variables are set as the optimal results in Table 3. Only the flow rate of LNG for pre-cooling and condensing should be adjusted to avoid temperature cross in pre-coolers and recondenser. As the daily evaporation rate of BOG changes from $0.03 \%$ to $0.1 \%$ with three LNG storage tanks of 160,000 cubic meters, the BOG flow rate varies from $2 \mathrm{t} / \mathrm{h}$ to $10 \mathrm{t} / \mathrm{h}$. The throughput of natural gas after ORV is $180 \mathrm{t} / \mathrm{h}$ for stable supply. Taking the proportion of BOG flow rate on natural gas output as the abscissa, total power consumptions of the processes are shown in Figure 8. Results indicate that the total power consumption increases linearly with the BOG flow rate. The power consumption of the re-condensation process with double-stage pre-cooling (case3 in Figure 8) is lower than that of the direct compression process (case1 in Figure 8) and the recondensation process with single-stage pre-cooling (case2 in Figure 8).

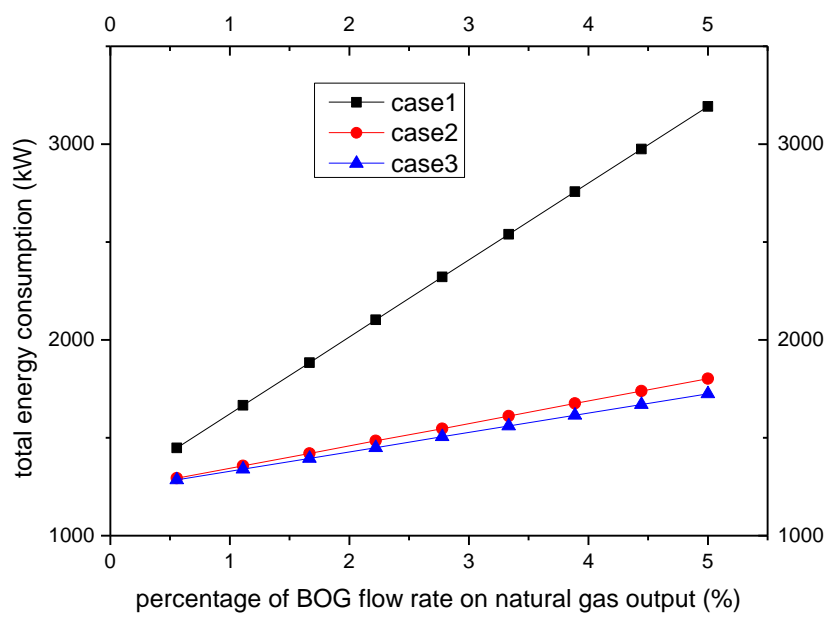

Figure 8. Sensitivity of the total power consumption respect to $B O G$ flow rate.

\section{Discussion}

It is assumed to be steady state during simulation. Although the BOG flow rate varies greatly during unloading and normal operation, the process can be regarded as steady state in batches, due to batchwise unloading from ships. Another assumption has been made that no pressure drop [5] occurs in heat exchangers to simplify the simulation in this study. However, heat exchanger will lead to pressure drop in reality process, which no doubt leads to higher power consumption. Heat exchanger efficiency can also affect the process performance. From literature review, spiral tube heat exchangers and plate-fin heat exchangers have been employed in natural gas liquefaction processes [22] for high efficiency. However, the typical shell and tube heat exchanger occupies incomparable advantages in application of high temperature and high pressure situations [23]. Since the pressure of the liquid side of heat exchangers is as high as $9000 \mathrm{kPa}$, a shell and tube heat exchanger is a good option in this process [22, 23]. The configuration and internal structure of heat exchangers will be studied in the future. The core equipment of this process is compressors and pumps, the adiabatic efficiency of which have been assumed to be $75 \%$. If more efficient compressors and pumps can be adopted in this process, system performance can be improved.

At the same time, the net positive suction head (NPSH) of pumps is not considered as a design parameter in the process, which should be noticed in pump design. Piping and connections must be sized and arranged to avoid highpressure pump cavitations. The installation height of the recondenser should be checked under practical conditions to guarantee the net power suction head of HP.

Meanwhile, zero boil off technology has received attention for storing cryogenic propellants in space [24, 25] by NASA. The solutions could be applied to the LNG industry in the future.

\section{Conclusions}

To improve the process performance for BOG treatment at $\mathrm{LNG}$ receiving terminals, a novel $\mathrm{BOG}$ re-condensation process with double-stage pre-cooling is presented in this paper. Energy balance and thermodynamic analysis are applied to the process. SRK equation and LKP equation are selected for the fluid package in Aspen HYSYS simulation. Taking the total power consumption as the objective function of process optimization, this process is optimized to achieve the total power consumption of $1598 \mathrm{~kW}$. Furthermore, the sensitivity of the process towards BOG flow rate is analyzed, indicating that the power consumption of this process is lower than that of direct compression process and the re-condensation process with single-stage pre-cooling. Several issues have been explained for engineering application of this process. Overall, this process shows to be effective for BOG treatment at LNG terminals.

\section{Acknowledgements}

This work is supported by oil and gas storage and transportation engineering department in Southwest Petroleum University, China.

\section{Nomenclature}

$\mathrm{h} \quad$ unit mass enthalpy $(\mathrm{kJ} / \mathrm{kg})$

$\mathrm{m}$ mass flow rate $(\mathrm{kg} / \mathrm{s})$

$\mathrm{p}$ pressure $(\mathrm{kPa})$

$\mathrm{Q}$ heat $(\mathrm{kW})$

$\mathrm{T}$ temperature $(\mathrm{K})$

$\mathrm{W} \quad$ power $(\mathrm{kW})$

\section{Symbols}

$\eta \quad$ the adiabatic efficiency

$\%$ percentage

\section{Subscripts}

$\begin{array}{ll}\mathrm{c} & \text { compressor } \\ \mathrm{p} & \text { pump } \\ \mathrm{rc} & \text { re-condenser }\end{array}$

\section{Acronyms}

BC BOG Compressor

BOG Boil-off Gas

BR BOG Re-condenser

HP High Pressure Pump

LKP Lee-Kesler-Plocker

LNG Liquefied Natural Gas

LP Low Pressure Pump

NPSH Net positive suction head

ORV Open Rack Vaporizer

SRK Soave-Redlich-Kwong 


\section{References}

[1] U.S. Energy Information Administration International energy outlook 2013 [Online], Available: http://www.eia.gov/forecasts/ieo/ (accessed May 5, 2014).

[2] Kumar, S., Kwon, H. T., Choi, K. H., Hyun Cho, J., Lim, W., and Moon, I., "Current status and future projections of LNG demand and supplies: A global prospective," Energy Policy, 39, 4097-4104, 2011.

[3] Lim, W., Choi, K., and Moon, I., "Current status and perspectives of liquefied natural gas (LNG) plant design," Industrial \& Engineering Chemistry Research, 52, 3065-3088, 2013.

[4] Lim, W., Lee, I., Tak, K., Cho, J. H., Ko, D., and Moon, I., "Efficient Configuration of a Natural Gas Liquefaction Process for Energy Recovery," Industrial \& Engineering Chemistry Research, 53, 1973-1985, 2014.

[5] He, T. B., Ju, Y. L., "A novel process for small-scale pipeline natural gas liquefaction," Applied Energy, 115, $17-24,2014$

[6] Tan, H., Li, Y., Tuo, H., Zhou, M., and Tian, B., "Experimental study on liquid/solid phase change for cold energy storage of Liquefied Natural Gas (LNG) refrigerated vehicle," Energy, 35, 1927-1935, 2010.

[7] Wang, M., Zhang, J., Xu, Q., and Li, K., "Thermodynamic-analysis-based energy consumption minimization for natural gas liquefaction," Industrial \& Engineering Chemistry Research, 50, 12630-12640, 2011.

[8] World's LNG liquefaction plants and regasification terminals, [Online], Available: www.globallnginfo.com (accessed May 10, 2014).

[9] Kumar, S., Kwon, H. T., Choi, K. H., Lim, W., Cho, J. H., Tak, K., and Moon, I, "LNG: An eco-friendly cryogenic fuel for sustainable development," Applied Energy, 88, 4264-4273, 2011.

[10] Mabuchi, N., "BOG reliquefaction with cold energy storage and utilization of LNG cold energy using cascade process," Energy Resour, 27, 334-336, 2006.

[11] Querol, E., Gonzalez-Regueral, B., García-Torrent, J., and García-Martínez, M. J., "Boil off gas (BOG) management in Spanish liquid natural gas (LNG) terminals," Applied Energy, 87, 3384-3392, 2010.

[12] Jung, M. J., Cho, J. H., and Ryu, W, "LNG terminal design feedback from operator's practical improvements," in The 22nd World Gas Congress, Tokyo, Japan, 2003.

[13] Shin, M. W., Shin, D., Choi, S. H., Yoon, E. S., and Han, C., "Optimization of the operation of boil-off gas compressors at a liquified natural gas gasification plant," Industrial \& Engineering Chemistry Research, 46, 6540-6545, 2007.

[14] Li, Y., Chen, X., "Dynamic Simulation for Improving the Performance of Boil-Off Gas Recondensation System at LNG Receiving Terminals," Chemical Engineering Communications, 199, 1251-1262, 2012.

[15] Yang, Z., Li, Y., "Optimization of boil-off gas recondensation process in LNG receiving terminal," Journal of Chemical Industry and Engineering, 60, 2876-2881, 2009. (In Chinese)

[16] Li, Y., Chen, X., and Chein, M. H., "Flexible and costeffective optimization of BOG (boil-off gas) recondensation process at LNG receiving terminals," Chemical Engineering Research and Design, 90, 15001505, 2012.

[17] Park, C., Song, K., Lee, S., Lim, Y., and Han, C., "Retrofit design of a boil-off gas handling process in liquefied natural gas receiving terminals," Energy, 44, 69-78, 2012.

[18] Chen, X. (2012). Modeling and Dynamic Optimization of Recondensation Process at LNG Receiving Terminals (Master's thesis), South China University of Technology, Guangzhou. (In Chinese)

[19] AspenTech. Aspen HYSYS user guides. V7.3 ed. Burlington (MA, USA); 2011.

[20] Gu, A., Lu, X., Wang, R., Shi, Y., and Lin, W., Liquefied Natural Gas Technology. Beijing: China Machine Press, 2004. (In Chinese)

[21] Cao, W. S., Lu, X. S., Lin, W. S., and Gu, A. Z., "Parameter comparison of two small-scale natural gas liquefaction processes in skid-mounted packages," Applied Thermal Engineering, 26, 898-904, 2006.

[22] Xu, Q. (2012). Study on Numerical Simulation of Heat Transfer Characteristic of Cryogenic Heat Exchanger in BOG Reliquefaction System (Master's thesis), South China University of Technology, Guangzhou. (In Chinese)

[23] Yang, Z. (2010). Optimization of the BOG recondensation process during the vessel transportation and storage of LNG (Master's thesis), South China University of Technology, Guangzhou. (In Chinese)

[24] Salerno, L. J., Gaby, J., Johnson, R., Kittel, P., and Marquardt, E. D., "Terrestrial applications of zero-boiloff cryogen storage," in Cryocoolers 11, Springer US, pp. 809-816, 2002.

[25] Plachta, D. W., Christie, R. J., Jurns, J. M., and Kittel, P., "ZBO cryogenic propellant storage applied to a Mars sample return mission concept," in ADVANCES IN CRYOGENIC ENGINEERING: Transactions of the Cryogenic Engineering Conference, AIP Publishing, pp. 205-212,2006. 